\title{
Providing Nutrition Care to Patients with Chronic Disease: An Irish Teaching Hospital Healthcare Professional Study
}

\author{
Laura Keaver (D), ${ }^{1}$ Ciara O’Meara, ${ }^{1}$ Mohsin Mukhtar, ${ }^{2}$ and Catherine McHugh ${ }^{2}$ \\ ${ }^{1}$ Department of Health and Nutritional Sciences, Institute of Technology, Sligo, Ireland \\ ${ }^{2}$ Sligo University Hospital, Sligo, Ireland \\ Correspondence should be addressed to Laura Keaver; keaver.laura@itsligo.ie
}

Received 21 May 2018; Revised 17 July 2018; Accepted 25 July 2018; Published 1 August 2018

Academic Editor: Friedrich Paul Paulsen

Copyright (c) 2018 Laura Keaver et al. This is an open access article distributed under the Creative Commons Attribution License, which permits unrestricted use, distribution, and reproduction in any medium, provided the original work is properly cited.

\begin{abstract}
An increasing prevalence of noncommunicable diseases (NCDs) and chronic illness is putting an ever increasing burden on healthcare services and delivery worldwide. Diet contributes significantly to the development of NCDs. Nutrition should therefore be viewed as an important aspect of patient care and be addressed by all healthcare professionals (HCPs). Previous work has highlighted a lack of competency around providing nutrition advice in HCPs; however, positive attitudes towards the importance of nutrition care are well documented in this group. The aim of this study is to document and compare Irish HCPs self-perceived competency towards incorporating nutrition care into practice. The NUTCOMP questionnaire was completed by 206 HCPs in Sligo University Hospital. The findings showed positive attitudes towards the incorporation of nutrition care into HCP practice; however, confidence in knowledge and skills was low, thus missing vital opportunities to prevent and/or treat chronic diseases and improve outcomes in acute illness. Previous nutrition education was associated with greater self-perceived knowledge about and skills in providing nutrition care to patients and positively associated with attitudes towards incorporating nutrition care into practice. HCPs expressed a desire and unmet need for additional and ongoing educational intervention in the area of nutritional intervention.
\end{abstract}

\section{Introduction}

An increasing prevalence of noncommunicable diseases (NCD) and chronic illness is putting an ever increasing burden on healthcare services and delivery worldwide [1]. Diet contributes significantly to the development of NCDs [2]; approximately $70 \%$ of adults are now overweight or obese and nutrition-related conditions account for greater than a quarter of all visits to primary care providers [3].

Nutrition should therefore be viewed as an important aspect of patient care and be addressed by all healthcare professionals (HCPs). Internationally, medical staff are viewed as a reliable and trusted source of information [4]. However, there has been an ad hoc approach to inclusion of nutrition educational programmes in medical and nursing curriculums in a number of countries $[5,6]$. A recent study found that out of six developed countries Ireland was the only one without any specific guidance or guidelines on nutrition competencies for inclusion in the undergraduate medical curricula [6]. In the five countries with guidance (UK, America, Canada, Australia, and New Zealand) there was little evidence of these guidelines being enforced [6]. Allied healthcare professionals aside from dietitians usually have no nutrition content included in their training, even though they have identified themselves as having a role in supporting the self-management of patients with long-term conditions and that this has the potential to include dietary advice [7].

Previous work has highlighted a lack of competency around providing nutrition advice in HCPs [8-10]; however positive attitudes towards the importance of nutrition care are well documented in this group [11-13]. The aim of this study is to document and compare Irish HCPs self-perceived competency towards incorporating nutrition care into dayto-day clinical practice and patient care. In order to better understand how to initiate and improve the delivery of nutrition information in clinical care, it is important that current area specific competency and attitudes are measured and understood. 


\section{Methods}

2.1. Overview. Competence can be defined as an individual's ability to perform a particular task and includes three components: knowledge, skill, and attitude [14]. Nutrition care refers to any healthcare professional who attempts to improve a patient's dietary intake and this could be for the prevention or management of lifestyle-related conditions $[15,16]$. This study utilized a cross-sectional survey to describe healthcare professional's knowledge, skills, and attitudes regarding the provision of nutrition care in clinical practice.

2.2. Survey Instrument. The validated NUTCOMP survey [17] was used to determine (1) confidence in knowledge about nutrition and chronic disease; (2) confidence in nutrition skills; and (3) attitudes towards nutrition care. The questions in each topic area were designed to broadly include all items that may be relevant in this area, rather than focusing on one condition or state, e.g., obesity. The survey also includes demographic and education questions to enable investigation of associations between these characteristics and HCPs selfperceived competency to provide nutrition care.

2.3. Data Collection. Surveys were distributed to all wards in Sligo University Hospital between March and September 2017.

2.4. Data Analysis. Data analysis was conducted using the SPSS statistical software package version 24 . Frequency distributions were calculated for each survey item, as well as mean and range for participants' years of experience. Knowledge and skills scores were calculated for each participant by adding up the scores assigned to each answer (not confident $=1$; not very confident $=2$; somewhat confident $=3$; very confident $=4$; and extremely confident $=5$ ). Attitude scores were similarly calculated where completely disagree $=1$; somewhat disagree $=2$; neither agree nor disagree $=3$; somewhat agree $=4$; and completely agree $=5$. Individuals were grouped into four groups: GP/GP trainees; hospital doctor; nurses/nurse students; allied health. Independent betweengroups ANOVA was used to determine any differences between these groups with regard to mean scores for knowledge, skills, and attitude. The data was tested for skewness and kurtosis and $\mathrm{z}$-values were calculated, all of which were within normal ranges.

The relationship between reported previous engagement in continuing education on the topic of nutrition or reported previous nutrition education and (1) confidence in knowledge about nutrition and chronic disease, (2) confidence in nutrition skills, and (3) attitudes towards nutrition care was investigated using Pearson's Chi-squared tests. In order to comply with the assumptions underpinning Chi-square tests, categories were collapsed to ensure that $<20 \%$ of cells remained below minimum counts. The Likert scale was collapsed into three groups: extremely or very confident; somewhat or not very confident; and no confidence. Pearson product-moment correlations were run to determine if there was a relationship between the three variables: knowledge, skills, and attitude. Statistical significance was set at $\mathrm{p} \leq 0.05$. Results are presented as mean $\pm \mathrm{SD}$.

2.5. Ethics. Ethical approval for this study was granted by Sligo University Hospital.

\section{Results}

A total of 206 HCPs completed the survey; 6 were excluded because of incomplete data; 4 additional questionnaires were excluded from the analysis for Tables 1 and 2 as profession was not indicated in the survey. These surveys were included in the analysis in Table 3, which did not differentiate between HCP. Allied health professionals are comprised of pharmacists, physiotherapists, occupational therapists, and healthcare assistants. Participant characteristics are displayed in Table 1.

The majority of participating professionals were female (71\%) aged between 25 and 44 years (68\%), with a mean job duration of $12( \pm 9.2)$ years. While $78 \%$ report completing a programme that contained some nutrition content, $78 \%$ also agreed or strongly agreed that there is a need for further nutrition education in their role. Only $28 \%$ have engaged in continuing education in the area of nutrition.

3.1. Knowledge. The mean score for confidence in knowledge about nutrition and chronic diseases was $19.6( \pm 4.8)$ out of a maximum 35, with the mean marks per HCP group outlined in Table 2. There was no significant difference between HCPs $(p=0.072)$. The area of greatest reported confidence was that of how body composition can impact the development of chronic disease (43\%). The majority of respondents were somewhat or not very confident for all the questions in the knowledge section. Previous nutrition education (Table 3 ) was positively associated with confidence in how body composition can impact the development of chronic disease, the interaction of various foods and nutrients with medications, and familiarity with the most recently published peerreviewed evidence regarding nutrition and chronic disease $(\mathrm{p}<0.05)$. Knowledge about food and medication interactions was also positively associated with previous engagement in continuing education on the topic of nutrition $(\mathrm{P}=<0.05)$.

3.2. Skills. The mean score for confidence in nutrition skills was $30.2( \pm 7.7)$ out of a maximum of 55 , with the mean marks per HCP group outlined in Table 2. There was a significant difference between groups $(\mathrm{p}=0.029)$ with allied health professionals demonstrating less confidence in their skills than the other professional groups. The majority of respondents $(62 \%)$ reported confidence in their ability to interpret biological data. With the exception of this skill, all other skills had the majority of respondents reporting being somewhat or not very confident. Previous nutrition education (Table 3 ) was positively associated with being more confident in the following skills: collecting information on the food an individual usually eats, recommending changes in food choices for an individual with chronic disease, determining appropriate food or nutrition goals for an individual with 
TABle 1: Participant characteristics $(\mathrm{n}=196)$.

\begin{tabular}{|c|c|c|c|}
\hline Category & Subcategory & Frequency & Percentage \\
\hline \multirow[t]{4}{*}{ Profession } & GP/GP trainee & 15 & 7.7 \\
\hline & Doctor/med student & 61 & 31.1 \\
\hline & Nurse/nurse student & 106 & 54.1 \\
\hline & Allied health $*$ & 14 & 7.1 \\
\hline \multirow[t]{2}{*}{ Gender } & Male & 58 & 29 \\
\hline & Female & 142 & 71 \\
\hline \multirow[t]{5}{*}{ Age } & $\leq 24$ years & 17 & 8.7 \\
\hline & $25-34$ years & 68 & 34.7 \\
\hline & $35-44$ years & 66 & 33.7 \\
\hline & $45-54$ years & 37 & 18.9 \\
\hline & $55+$ & 8 & 4.1 \\
\hline Current job duration (years) & Mean \pm SD $=12.1 \pm 9.2$ & $\begin{array}{c}\text { Range }<1 \text { year to } 38 \\
\text { years }\end{array}$ & \\
\hline \multirow[t]{3}{*}{$\begin{array}{l}\text { Previous nutrition education } \\
(\mathrm{n}=186)\end{array}$} & $\begin{array}{l}\text { Completion of a programme that did not } \\
\text { contain any nutrition content }\end{array}$ & $x_{1}$ & 21 \\
\hline & $\begin{array}{l}\text { Completion of a programme that } \\
\text { contained some nutrition content }\end{array}$ & 145 & 78 \\
\hline & $\begin{array}{l}\text { Completion of a programme that was } \\
\text { predominantly focused on nutrition }\end{array}$ & 2 & 1 \\
\hline \multirow{2}{*}{$\begin{array}{l}\text { Previous engagement in continuing } \\
\text { education on the topic of nutrition }\end{array}$} & yes & 54 & 27.6 \\
\hline & no & 142 & 72.4 \\
\hline Need of further & Strongly disagree & 17 & 8.6 \\
\hline \multirow[t]{4}{*}{ nutrition education } & Disagree & 6 & 3 \\
\hline & Neither agree nor disagree & 20 & 10.2 \\
\hline & Agree & 101 & 51.3 \\
\hline & Strongly agree & 53 & 26.9 \\
\hline
\end{tabular}

* Allied health professionals are comprised of pharmacists, physiotherapists, occupational therapists, and healthcare assistants.

TABLE 2: Comparison of self-reported nutrition care competence between GP/GP trainees; doctor/med students; nurse/nurse students, and allied health professionals.

\begin{tabular}{|c|c|c|c|c|c|c|}
\hline Category & Profession & $\mathrm{n}$ & Mean & SD & $\mathrm{F}$ & $\mathrm{P}$ \\
\hline \multirow{4}{*}{ Knowledge $($ maximum $=35)$} & GP/GP trainee & 15 & 18.3 & 3.5 & \multirow{4}{*}{2.36} & \multirow{4}{*}{0.072} \\
\hline & Doctor/med student & 61 & 20.5 & 4.7 & & \\
\hline & Nurse/nurse student & 106 & 19.6 & 4.6 & & \\
\hline & Allied & 14 & 17.1 & 6.7 & & \\
\hline \multirow{4}{*}{ Skills (maximum $=55$ ) } & GP/GP trainee & 15 & 30.3 & 6.6 & \multirow{4}{*}{3.085} & \multirow{4}{*}{0.029} \\
\hline & Doctor/med student & 59 & 30.4 & 7.0 & & \\
\hline & Nurse/nurse student & 103 & 30.7 & 7.6 & & \\
\hline & Allied & 14 & 24.2 & 10.2 & & \\
\hline \multirow{4}{*}{ Attitude $($ maximum $=40)$} & GP/GP trainee & 14 & 34 & 3.3 & \multirow{4}{*}{3.847} & \multirow{4}{*}{0.011} \\
\hline & Doctor/med student & 59 & 34.3 & 4.9 & & \\
\hline & Nurse/nurse student & 106 & 35.9 & 3.7 & & \\
\hline & Allied & 12 & 32.8 & 4.9 & & \\
\hline
\end{tabular}

chronic disease, and formulating a meal plan for an individual with chronic disease $(\mathrm{p}=<0.05)$.

3.3. Attitude. When questioned on attitudes towards nutrition care respondents had a mean score of $35( \pm 4.2)$ out of a maximum of 40 , with the mean marks per HCP group outlines in Table 2 . There was a significant difference between groups $(p=0.011)$ with nurses having the most positive attitude towards nutrition care. The majority of participants (71\%-95\%) somewhat or completely agreed with all 
TABLE 3: Healthcare professionals knowledge, skills, and attitude, ranked in order of agreement.

\begin{tabular}{|c|c|c|c|}
\hline Items & $\begin{array}{l}\text { Extremely or very } \\
\text { confident } \\
\mathrm{n}(\%)\end{array}$ & $\begin{array}{l}\text { Somewhat or not very } \\
\text { confident } \\
\mathrm{n}(\%)\end{array}$ & $\begin{array}{l}\text { No confidence } \\
\mathrm{n}(\%)\end{array}$ \\
\hline \multicolumn{4}{|l|}{ Knowledge } \\
\hline $\begin{array}{l}\text { How body composition can impact the development of } \\
\text { chronic disease }\end{array}$ & $85(42.7)$ & $108(54.3)$ & $6(3)$ \\
\hline $\begin{array}{l}\text { How food and nutrients influence development and } \\
\text { management of chronic disease }\end{array}$ & $69(34.5)$ & $125(62.5)$ & $6(3)$ \\
\hline $\begin{array}{l}\text { How different body systems are affected by foods and } \\
\text { nutrients }\end{array}$ & $65(32.5)$ & $128(64)$ & $7(3.5)$ \\
\hline $\begin{array}{l}\text { Guidelines for nutrition related management of specific } \\
\text { chronic diseases }\end{array}$ & $46(23.2)$ & $139(70.2)$ & $13(6.6)$ \\
\hline Irish healthy eating guidelines & $41(21)$ & $135(69.3)$ & $19(9.7)$ \\
\hline How foods and nutrients interact with medications $s^{\mathrm{a}, \mathrm{b}}$ & $30(15)$ & $151(75.5)$ & $19(9.5)$ \\
\hline $\begin{array}{l}\text { The most recently published peer-reviewed evidence } \\
\text { regarding nutrition and chronic disease }{ }^{b}\end{array}$ & $12(6)$ & $112(56.3)$ & $75(37.7)$ \\
\hline \multicolumn{4}{|l|}{ Skills } \\
\hline Interpret biological data & $121(62)$ & $69(35.4)$ & $5(2.6)$ \\
\hline Collect information on the food an individual usually eats ${ }^{\mathrm{b}}$ & $85(43.6)$ & $104(53.3)$ & $5(2.6)$ \\
\hline Interpret compositional data & $82(42.2)$ & $103(53.1)$ & $9(4.6)$ \\
\hline $\begin{array}{l}\text { Maintain clear and concise records regarding the nutrition } \\
\text { related assessment and advice provided to individuals }\end{array}$ & $42(21.7)$ & $127(65.5)$ & $24(12.4)$ \\
\hline $\begin{array}{l}\text { Provide nutrition care that results in improvements in the } \\
\text { food that an individual usually eats }\end{array}$ & $42(21.6)$ & $137(70.6)$ & $15(7.7)$ \\
\hline $\begin{array}{l}\text { Recommend changes in food choices for an individual } \\
\text { with chronic disease }^{\mathrm{b}}\end{array}$ & $34(17.5)$ & $137(70.3)$ & $24(12.3)$ \\
\hline $\begin{array}{l}\text { Determine appropriate food or nutrition goals for an } \\
\text { individual with chronic disease }{ }^{b}\end{array}$ & $29(15)$ & $140(72.1)$ & $25(12.9)$ \\
\hline $\begin{array}{l}\text { Monitor and evaluate changes over time regarding the } \\
\text { food an individual usually eats }\end{array}$ & $28(14.4)$ & $142(72.8)$ & $24(12.3)$ \\
\hline $\begin{array}{l}\text { Use the Irish guide to healthy eating to evaluate the } \\
\text { appropriateness of an individuals food intake }\end{array}$ & $24(12.3)$ & $134(69.1)$ & $36(18.6)$ \\
\hline $\begin{array}{l}\text { Access the most recently published peer-reviewed } \\
\text { evidence regarding nutrition and chronic disease }\end{array}$ & $24(12.3)$ & $142(72.8)$ & $29(14.9)$ \\
\hline $\begin{array}{l}\text { Formulate a meal plan for an individual with chronic } \\
\text { disease }^{\text {b }}\end{array}$ & $18(9.2)$ & $122(62.9)$ & $54(27.8)$ \\
\hline \multicolumn{4}{|l|}{ Attitude } \\
\hline & $\begin{array}{c}\text { Somewhat or } \\
\text { completely agree } \\
\mathrm{n}(\%)\end{array}$ & $\begin{array}{l}\text { Neither agree nor } \\
\text { disagree } \\
\mathrm{n}(\%) \\
\end{array}$ & $\begin{array}{c}\text { Somewhat or } \\
\text { completely disagree } \\
\mathrm{n}(\%)\end{array}$ \\
\hline $\begin{array}{l}\text { If the topic arises, it is important that I encourage my } \\
\text { patients/clients to eat healthy food }\end{array}$ & $186(95.3)$ & $8(4.1)$ & $1(0.5)$ \\
\hline $\begin{array}{l}\text { It is important that I encourage my patients to seek } \\
\text { support from other health professionals if I am unable to } \\
\text { meet their nutrition-related needs }{ }^{\text {b }}\end{array}$ & $186(95.4)$ & $6(3.1)$ & $3(1.5)$ \\
\hline $\begin{array}{l}\text { It is important that all individuals usually eat healthy foods } \\
\text { regardless of age, body weight and activity levels }{ }^{\mathrm{b}}\end{array}$ & $182(93.3)$ & $6(3.1)$ & $7(3.6)$ \\
\hline $\begin{array}{l}\text { It is important that I take every opportunity possible to } \\
\text { encourage my patients/clients to eat healthy foods }\end{array}$ & $182(93.3)$ & $8(4.1)$ & $5(2.6)$ \\
\hline $\begin{array}{l}\text { Encouraging my patients to eat healthy foods is within my } \\
\text { scope of practice }\end{array}$ & $167(85.7)$ & $22(11.3)$ & $6(3.1)$ \\
\hline $\begin{array}{l}\text { Encouraging my patients/clients to eat healthy foods is an } \\
\text { effective use of my professional time }\end{array}$ & $166(85.6)$ & 23 (11.9) & $5(2.6)$ \\
\hline $\begin{array}{l}\text { Providing specific nutrition recommendations to my } \\
\text { patients that can assist with managing their chronic } \\
\text { disease is an effective use of my time }\end{array}$ & $158(81.5)$ & $21(10.8)$ & $15(7.7)$ \\
\hline
\end{tabular}


TABLE 3: Continued.

\begin{tabular}{lcc}
\hline Items & $\begin{array}{c}\text { Extremely or very } \\
\text { confident } \\
\mathrm{n}(\%)\end{array}$ & $\begin{array}{c}\text { Somewhat or not very } \\
\text { confident } \\
\mathrm{n}(\%)\end{array}$ \\
\hline $\begin{array}{l}\text { Providing specific nutrition recommendations to my } \\
\text { patients that can assist with managing their chronic } \\
\text { disease is within the scope of my practice }\end{array}$ & $139(71.3)$ & $27(13.8)$ \\
\hline $\begin{array}{l}{ }^{\mathrm{a}} \text { Positively associated with previous engagement in continuing education on the topic of nutrition }(\mathrm{p}<0.05) . \\
\mathrm{b} \text { Positively associated with previous nutrition education }(\mathrm{p}<0.05) .\end{array}$
\end{tabular}

statements. Previous nutrition education (Table 3) is positively associated with the opinion that it is important that they encourage patients/clients to eat healthy food, to seek support from other health professionals if the respondent feels unable to meet their nutrition-related needs, and a recognition that it is important that all individuals regularly eat healthy foods regardless of age, body weight, and activity levels $(\mathrm{p}<0.05)$.

3.4. Relationship between Knowledge, Skills, and Attitude. There was a strong, positive correlation between knowledge and skills $(r=.673, n=195, p=.000)$, while only a weak positive correlation was found between skills and attitude $(r=$ $.175, n=195, p=.016)$ and between knowledge and attitude $(r$ $=.138, n=195, p=.055)$.

\section{Discussion}

To our knowledge, this is the first study to assess selfperceived knowledge and skills competency in nutrition as well as attitudes towards incorporating nutrition into chronic disease care in Irish HCPs. The findings showed positive attitudes towards the incorporation of nutrition care into HCP practice, but confidence in knowledge and skills was low.

HCPs are required, and justly so, to keep up to date with clinical practice guidelines in a variety of specialities as well as best practice guidelines in their profession, thus requiring a need for career-long learning to maintain evidence-based knowledge and skills [18]. Despite this, only $6 \%$ of this cohort were very confident in their ability to remain up to date with the most recently published peer-reviewed evidence regarding nutrition and chronic disease. Further research would be beneficial to study the perceived barriers to ongoing education and learning in the healthcare setting to ensure the delivery of international best practice in healthcare in Ireland.

The skill with the most reported confidence was that of interpreting biological data, a skill underpinning most, if not all, HCP roles. Low levels of confidence were reported in areas such as promoting suitable food or nutrition goals, monitoring food consumption, translating the Irish food pyramid into practical advice, and formulating meal plans. Previous studies have similarly shown low confidence in nutrition knowledge and skills [19-23]. It was also clear from the findings that previous nutrition education experiences are important in affecting confidence about nutrition care, with those who reported previous education in nutrition having more confidence in certain areas of their knowledge and skills. In addition, the majority of participants (78\%) agreed or strongly agreed with the statement that they need further nutrition education.

We should be prioritizing nutrition and lifestyle education not only to treat but also to prevent chronic disease. Globally we aim to reduce the incidence of noncommunicable disease by 2025 [24]; to achieve this nutrition needs to be included as a first line intervention [25-27]. For this to occur dietary advice needs to become more accessible in healthcare settings. Currently, a patient must be referred to see a dietician to receive nutrition advice [28]. GPs and doctors can justify this referral in most cases only if a patient is experiencing serious risks or has been diagnosed with a condition such as diabetes or coeliac disease where nutrition plays an integral role in the management of the condition.

Currently, therefore, expert nutritional advice in the Irish healthcare system tends to be, by default, interventional. It is a response rather than a solution. Overweight and obesity are well recognised modifiable risk factors for early morbidity and mortality $[29,30]$; however as shown in this study, even though in terms of knowledge the area of greatest reported confidence was that of how body composition can impact the development of chronic disease, there was still only $43 \%$ of individuals confident in their knowledge of this area.

Very positive attitudes towards the incorporation of nutrition information were found and this was found to be higher in nurses than other HCPs; this is not a surprising result given that nurses can work quite closely with dietitians in the hospital setting providing insight into appetite, demeanour, dietary intake, bowel motions, and weight changes of patients. These results mirror those found elsewhere with healthcare professionals worldwide reporting an interest in and an awareness of the importance of nutrition in this setting $[12,13,31,32]$.

It could be concluded from this study and others that HCPs do not feel adequately trained to address diet and nutrition-related issues with their patients, thus missing vital opportunities to prevent and/or treat chronic diseases and improve outcomes in acute illness. They do however recognise the importance of nutrition and have positive attitudes towards its incorporation into care as well as an interest in further education in the area.

4.1. Limitations. The strategy used to recruit participants could have contributed to selection bias; individuals who agreed to complete the survey may have had a particular interest in nutrition which could have skewed the results. In addition, a response rate could not be calculated as it is 
unknown how many HCPs read the survey and chose not to participate. Finally, the self-report aspect of this survey could have led to participants reporting socially desirable outcomes rather than a true reflection of their skills and attitudes.

4.2. Future Directions. Nutrition summer schools and weekend courses in nutrition provided in the UK to undergraduate medical students have proven very popular and provide opportunity to engage future healthcare professionals at an early stage in training [33]. It does however rely on an individual being interested enough to apply for and then attend this course in their free time. It is vital that future research determines whether nutrition-focused training results in an improvement in the effectiveness of nutrition care provided by HCPs and subsequently the health outcomes of patients in their care.

Making every contact count [34] is an initiative originally designed for HCPs and now being expanded for inclusion in primarily medical and nursing degree programmes with a longer term goal of educating all undergraduate HCPs and health promoters. The curriculum focusses on encouraging the HCP to ask patients about lifestyle behaviours related to chronic disease and includes education in the areas of tobacco use, alcohol and drug use, diet, and physical activity and it will be interesting to see if this improves confidence and competency in the delivery of nutrition information as well as these other important health promoting areas.

\section{Conclusion}

This study shows positive attitudes towards the incorporation of nutrition into clinical care as well as an appetite for professional development in the area; however confidence is currently low.

\section{Data Availability}

The data used to support the findings of this study are available from the corresponding author upon request.

\section{Disclosure}

This project received no specific funding and was carried out voluntarily by the authors.

\section{Conflicts of Interest}

The authors declare no conflicts of interest.

\section{Acknowledgments}

The authors wish to acknowledge all the healthcare professionals who took the time to complete the questionnaire and contribute to this study.

\section{References}

[1] D. Maher, N. Ford, and N. Unwin, "Priorities for developing countries in the global response to non-communicable diseases," Globalization and Health, vol. 8, article no. 14, 2012.
[2] M. Ezzati and E. Riboli, "Behavioral and dietary risk factors for noncommunicable diseases," The New England Journal of Medicine, vol. 369, no. 10, pp. 954-964, 2013.

[3] K. M. Kolasa and K. Rickett, "Barriers to providing nutrition counseling cited by physicians: a survey of primary care practitioners," Nutrition in Clinical Practice, vol. 25, no. 5, pp. 502-509, 2010.

[4] L. Ball, B. Desbrow, and M. Leveritt, "An exploration of individuals' preferences for nutrition care from Australian primary care health professionals," Australian Journal of Primary Health, vol. 20, no. 1, pp. 113-120, 2014.

[5] N. P. Morris, "The neglect of nutrition in medical education: a firsthand look," JAMA Internal Medicine, vol. 174, no. 6, pp. 841842, 2014.

[6] J. Crowley, L. Ball, C. Laur et al., "Nutrition guidelines for undergraduate medical curricula: a six-country comparison," Advances in Medical Education and Practice, no. 6, pp. 127-133, 2015.

[7] J. McClinchey, J. Williams, L. Gordon, M. Cairns, and G. Fairey, Dietary Advice and Collaborative Working: Do Pharmacists and Allied Health Professionals Other Than Dietitians Have a Role? Healthcare, vol. 3, 2015.

[8] R. Perlstein, S. McCoombe, C. Shaw, and C. Nowson, "Medical students' perceptions regarding the importance of nutritional knowledge and their confidence in providing competent nutrition practice," Public Health, vol. 140, pp. 27-34, 2016.

[9] M. Castillo, R. Feinstein, J. Tsang, and M. Fisher, "Basic nutrition knowledge of recent medical graduates entering a pediatric residency program," International Journal of Adolescent Medicine and Health, vol. 28, no. 4, pp. 357-361, 2016.

[10] K. Glanz, "Review of nutritional attitudes and counseling practices of primary care physicians," American Journal of Clinical Nutrition, vol. 65, no. 6, pp. 2016S-2019S, 1997.

[11] L. E. Ball, R. M. Hughes, and M. D. Leveritt, "Nutrition in general practice: role and workforce preparation expectations of medical educators," Australian Journal of Primary Health, vol. 16, no. 4, pp. 304-310, 2010.

[12] M. L. Vetter, S. J. Herring, M. Sood, N. R. Shah, and A. L. Kalet, "What do resident physicians know about nutrition? An evaluation of attitudes, self-perceived proficiency and knowledge," Journal of the American College of Nutrition, vol. 27, no. 2, pp. 287-298, 2008.

[13] T. V. Mihalynuk, C. S. Scott, and J. B. Coombs, "Self-reported nutrition proficiency is positively correlated with the perceived quality of nutrition training of family physicians in Washington State," American Journal of Clinical Nutrition, vol. 77, no. 5, pp. 1330-1336, 2003.

[14] S. Verma, M. Paterson, and J. Medves, "Core competencies for health care professionals: what medicine, nursing, occupational therapy, and physiotherapy share," Journal of Allied Health, vol. 35, no. 2, pp. 109-115, 2006.

[15] L. Ball, R. Hughes, B. Desbrow, and M. Leveritt, "Patients' perceptions of nutrition care received from general practitioners: focus on type 2 diabetes," Family medicine, vol. 29, pp. 719-725, 2012.

[16] "Series: Diet, Nutrition, and the Prevention of Chronic Diseases," Tech. Rep., World Health Organization,, World Health Organization. WHO, Geneva, Switzerland, 2003.

[17] L. E. Ball and M. D. Leveritt, "Development of a validated questionnaire to measure the self-perceived competence of primary health professionals in providing nutrition care to patients with 
chronic disease," Journal of Family Practice, vol. 32, no. 6, pp. 706-710, 2015.

[18] Health and Care Professions Council, Continuing Professional Development and Your Registration, Health and Care Professions Council, Health and Care Professions Council, London, UK, 2012.

[19] P. M. Kris-Etherton, S. R. Akabas, C. W. Bales et al., "The need to advance nutrition education in the training of health care professionals and recommended research to evaluate implementation and effectiveness," American Journal of Clinical Nutrition, vol. 99, no. 5, pp. 1153S-1166S, 2014.

[20] J. Frenk, L. Chen, Z. A. Bhutta et al., "Health professionals for a new century: transforming education to strengthen health systems in an interdependent world," The Lancet, vol. 376, no. 9756, pp. 1923-1958, 2010.

[21] K. M. Adams, M. Kohlmeier, and S. H. Zeisel, "Nutrition education in U.S. medical schools: latest update of a national survey," Academic Medicine: Journal of the Association of American Medical Colleges, vol. 85, no. 9, pp. 1537-1542, 2010.

[22] M. Mowe, I. Bosaeus, H. H. Rasmussen et al., "Insufficient nutritional knowledge among health care workers?" Clinical Nutrition, vol. 27, no. 2, pp. 196-202, 2008.

[23] M. W. Persenius, M.-L. Hall-Lord, C. Bååth, and B. W. Larsson, "Assessment and documentation of patients' nutritional status: Perceptions of registered nurses and their chief nurses," Journal of Clinical Nursing, vol. 17, no. 16, pp. 2125-2136, 2008.

[24] World Health Organisation, Global Action Plan for The Prevention And Control of Noncommunicable Diseases, 2013-2020, World Health Organisation, Geneva, Switzerland, 2013.

[25] WHO/FAO Joint Consultation, Diet, Nutrition And The Prevention of Chronic Diseases: Report of A Joint WHO/FAO Expert Consultation, WHO, Geneva, Switzerland, 2003.

[26] M. Hartley, "Lifestyle Modification as First Line of Treatment for Chronic Disease," Journal of Diabetes, Metabolic Disorders \& Control, vol. 1, no. 2, 2014.

[27] National Academy of Medicine, Chronic Disease Prevention: Tobacco, Physical Activity, and Nutrition for a Healthy Start A Vital Direction for Health and Health Care, Perspectives - Expert Voices in Health \&amp; Health Care, 2016, https://nam .edu/wp-content/uploads/2016/09/Chronic-Disease-Prevention-Tobacco-Physical-Activity-and-Nutrition-for-a-HealthyStart.pdf.

[28] Health Service Executive, "Dietitian," 2017, https://www.hse.ie/ eng/services/list/2/primarycare/pcteams/dublinsouthpcts/dunlaoghaireglasthulepct/dietitian.html.

[29] E. D. Grande, T. Gill, L. Wyatt, C. R. Chittleborough, P. J. Phillips, and A. W. Taylor, "Population attributable risk (PAR) of overweight and obesity on chronic diseases: South Australian representative, cross-sectional data," Obesity Research \& Clinical Practice, vol. 3, no. 3, pp. 159-168, 2009.

[30] P. W. Wilson, R. B. D’Agostino, L. Sullivan, H. Parise, and W. B. Kannel, "Overweight and obesity as determinants of cardiovascular risk; the Framingham experience," JAMA Internal Medicine, vol. 162, pp. 1867-1872, 2002.

[31] J. Crowley, L. Ball, D. Y. Han et al., "Doctors' attitudes and confidence towards providing nutrition care in practice: Comparison of New Zealand medical students, general practice registrars and general practitioners," Journal of Primary Health Care, vol. 7, no. 3, pp. 244-250, 2015.

[32] J. Crowley, L. Ball, D. Y. Han, B. Arroll, M. Leveritt, and C. Wall, "New zealand medical students have positive attitudes and moderate confidence in providing nutrition care: a crosssectional survey," Journal of Biomedical Education, vol. 2015, Article ID 259653, 7 pages, 2015.

[33] S. Ray, R. Udumyan, M. Rajput-Ray et al., "Evaluation of a novel nutrition education intervention for medical students from across England," BMJ Open, vol. 2, Article ID e000417, 2012.

[34] Health Service Executive, Making Every Contact Count: A Health Behaviour Change Framework and Implementation Plan for Health Professionals in the Irish Health Service, Health Service Executive, 2016. 


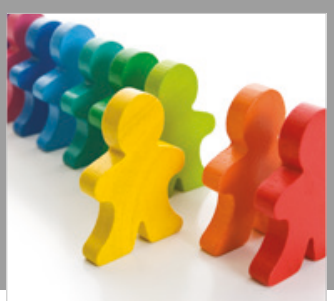

Autism

Research and Treatment
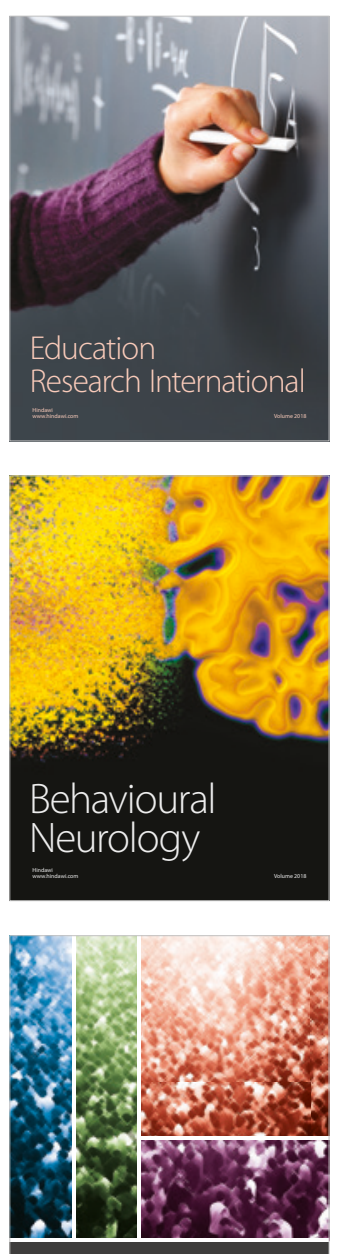

International Journal of

Population Research

$\underline{-m}$

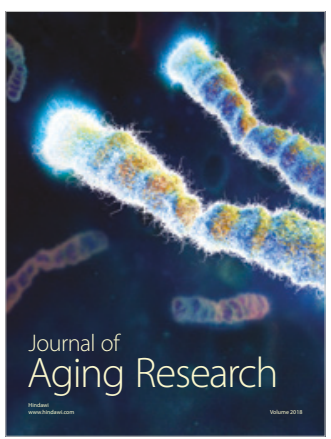

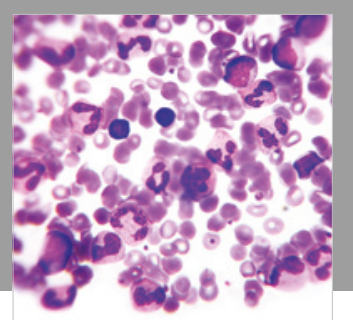

Pathology

Research International$$
=
$$

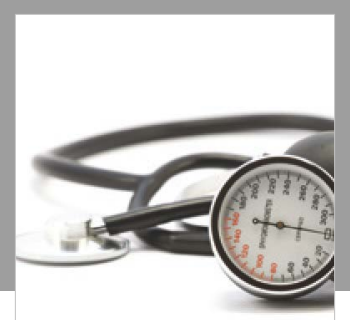

Nursing

Research and Practice

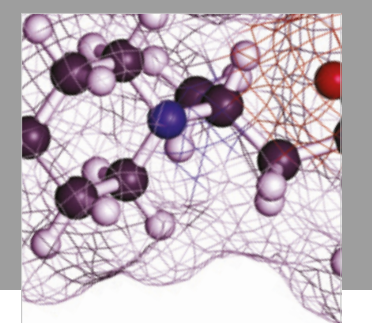

Pain

Research and Management

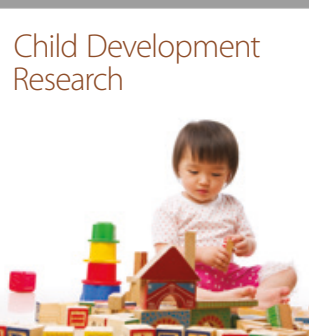

बाD

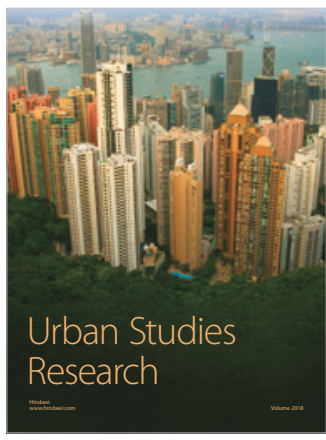

\section{Hindawi}

Submit your manuscripts at

www.hindawi.com
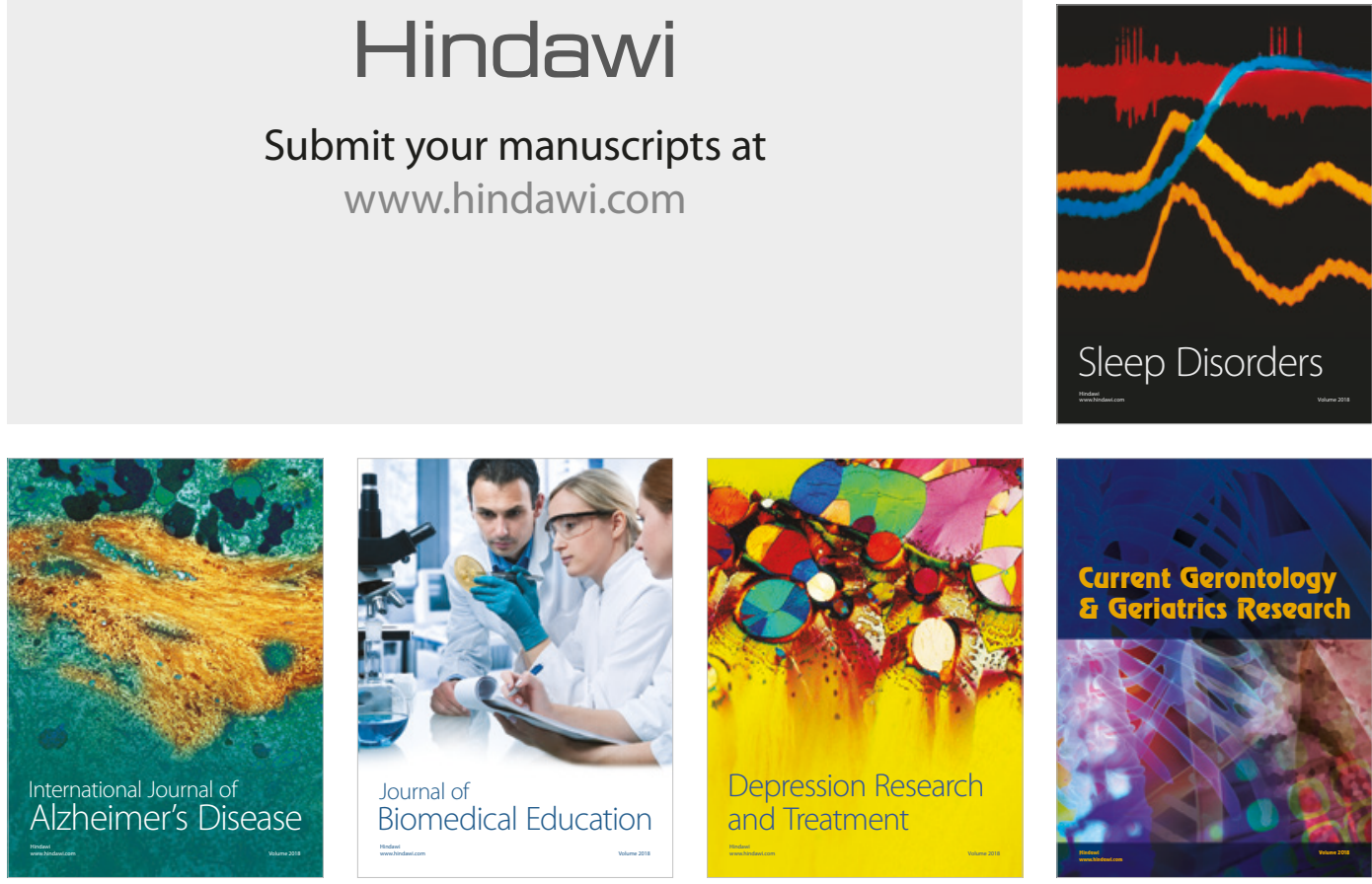

Journal of

Biomedical Education

$=$

smman

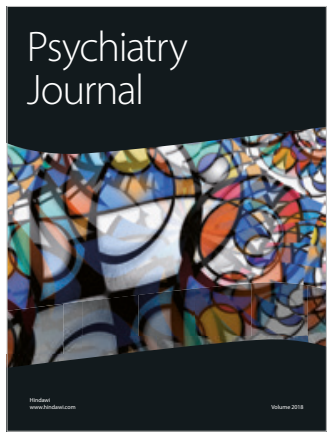

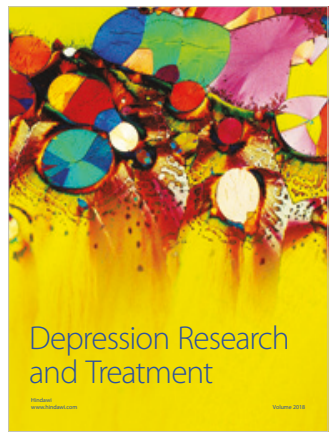
